
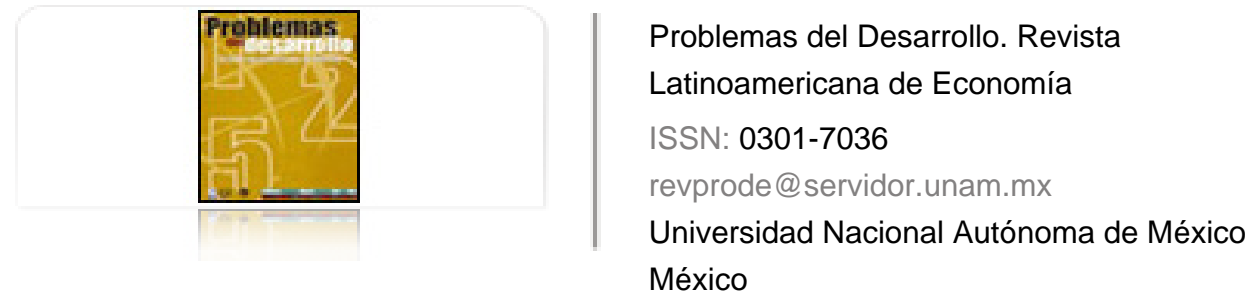

Mercado, Alexis; Testa, Pablo

Los senderos de la transformación productiva de América Latina

Problemas del Desarrollo. Revista Latinoamericana de Economía, vol. 34, núm. 133, 2003, pp. 129-

155

Universidad Nacional Autónoma de México

Distrito Federal, México

Disponible en: http://www.redalyc.org/articulo.oa?id=11825949013

Cómo citar el artículo

- Número completo

- Más información del artículo

Página de la revista en redalyc.org

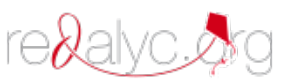

Sistema de Información Científica

Red de Revistas Científicas de América Latina, el Caribe, España y Portugal Proyecto académico sin fines de lucro, desarrollado bajo la iniciativa de acceso abierto 


\section{LOS SENDEROS DE LA TRANSFORMACIÓN PRODUCTIVA DE AMÉRICA LATINA*}

\section{Alexis Mercado** Pablo Testa***}

Fecha de recepción: 29 de agosto de 2002. Fecha de autorización: 30 de octubre de 2003.

\section{Resumen}

Se estudian las implicaciones del modelo de desarrollo adoptado en América Latina en los últimos años. El estancamiento de diversos indicadores socieconómicos evidencia un retroceso alarmante en el bienestar de la población. Lo anterior, aunado al desempeño económico de la mayoría de los países durante los años noventa, caracterizado por un progresivo debilitamiento de la manufacturas y el fortalecimiento de actividades de extracción y transformación primaria, configuran un perfil de desarrollo cuestionable en términos de sustentabilidad. Sin embargo, en América Latina se refuerza una estructura primaria exportadora sin mayores consideraciones acerca de las implicaciones ambientales de su explotación.

Palabras clave: transformación productiva, desarrollo sustentable, paradigma productivo-ambiental.

\section{Abstract}

This paper studies the implications for sustainability from the development model adopted in Latin America during recent years. The stagnation of various socioeconomic indicators reveals an alarming step backward for the well-being of populations. This, added to the economic situation for most of the countries during the 1990's which was characterized by progressive weakening of manufacturing and the strengthening of extraction and primary transformation activities, creates a development profile that is questionable in terms of sustainability. Nevertheless, in Latin America a primary export structure is reinforced, without much thought given to the implications for the environment from such exploitation.

Key words: productive transformation, sustainable development, productive-environmental paradigm.

** Químico, PhD en Estudios de la Ciencia. Profesor investigador, Área de Ciencia y Tecnología, Centro de Estu dios del Desarrollo (cENDEs), Universidad Central de Venezuela. Correo electrónico: amercado@cantv.net

*** Estadístico, MSc en Planificación del Desarrollo. Área de Ciencia y Tecnología, Centro de Estudios del Desa rrollo (CENDEs), Universidad Central de Venezuela. Correo electrónico: ptesta@cantv.net 


\section{Résumé}

Les implications du modèle de développement adopté en Amérique Latine pour les dernières années en termes de soutenabilité sont ici étudiées. La stagnation de divers indicateurs socioéconomiques rend évidente une rétrocession alarmante quant au bien-être de la population. Ceci, ajouté au déroulement économique de la plupart des pays au cours des années quatrevingt-dix, caractérisé par un affaiblissement progressif des manufactures et par le renforcement des activités d'extraction et de transformation primaires, forment un profil de développement à mettre en question en termes de soutenabilité. Cependant en Amérique latine, une structure primaire d'exportation se trouve renforcée, sans prendre en compte les implications environnementales liées à son exploitation.

Mots-cléfs: transformation productive, développement soutenable, paradigme productivoenvironnemental.

\section{Resumo}

Estudam-se as implicações do modelo de desenvolvimento adotado na América Latina nos últimos anos, em termos de sustentabilidade. A estagnação de vários indicadores sócioeconômicos evidenciam um retrocesso alarmante no bem-estar da população. Isto, unido ao desempenho econômico da maioria dos países durante os anos noventa, caracterizado por um progressivo enfraquecimento das manufaturas e o fortalecimento de atividades de extração e transformação primária, configuram um perfil de desenvolvimento questionável em termos de sustentabilidade. Porém, na América Latina está sendo reforçada uma estrutura primária exportadora sem maiores considerações às implicações ambientais da sua exploração.

Palavras chave: transformação produtiva, desenvolvimento sustentável, paradigma produtivoambiental. 


\section{Introducción}

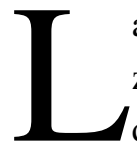

a catastrófica caída de la economía argentina a finales de 2001, fielmente organizada dentro de los lineamientos de liberalización económica propuestos por los diferentes organismos multilaterales y una promesa de modernización, constituye, quizás, la demostración más evidente de la ineficacia de esta concepción política para resolver los agudos problemas socioeconómicos de los países en vías de desarrollo. Ni qué decir entonces acerca de la posibilidad de superar, dentro de este esquema, los problemas de carácter ambiental.

Por su parte, las masivas e intensas manifestaciones de diversas organizaciones no gubernamentales en contra de las políticas de los organismos multilaterales que, desde 1999, vienen ocurriendo reiteradamente en el ámbito de los foros económicos internacionales, revelan el malestar generalizado con relación a los efectos negativos que estas políticas han generado en términos sociales y ambientales a escala global. ${ }^{1}$ Esas manifestaciones sorprenden, aún más, por el hecho de que no provienen de grupos políticos y organizaciones no gubernamentales de los atribulados países en vías de desarrollo, sino de importantes agrupaciones sociales de países que han alcanzado altos niveles de desarrollo social y económico.

Por otra parte, organismos como el Fondo Monetario Internacional y el Banco Mundial han comenzado a aceptar una cuota de responsabilidad por el agrandamiento de la brecha entre ricos y pobres —entiéndase entre personas ricas y personas pobres, entre países ricos y países pobres y entre continentes ricos y continentes pobres- ${ }^{2}$ Asimismo, el Banco Interamericano de Desarrollo reconoce que en los últimos años mantuvo una excesiva preocupación por el control del déficit fiscal y el equilibrio de las cuentas públicas, olvidándose de la necesaria inversión social que deben realizar los Estados. Estas autocríticas evidencian las profundas incoherencias de los modelos de desarrollo imperantes a escala global y la necesidad de generar cambios importantes en sus concepciones y estructuras.

En medio de este confuso panorama de inicios de siglo, se le plantean a América Latina serios desafíos en prácticamente todos los órdenes de la vida social. La resolución de ingen-

Destacan por su intensidad las acontecidas en la cumbre de la Organización Mundial de Comercio en Seattle en diciembre de 1999, en Washington en abril de 2000, en el Foro Económico Mundial de Davos en enero de 2001 y la trágica reunión del G7 en Génova en julio de 2001.

2 Joseph Stiglitz (2000), ex director del вм у premio Nobel de Economía 2001 se ha convertido en uno de los críticos más agudos de estos organismos, llegando a afirmar que sus políticas coadyuvan al deterioro econó mico y social de las naciones sometidas a sus lineamientos. 
tes problemas y la satisfacción de necesidades básicas de vastos sectores de la población constituyen prioridades que difícilmente puedan posponerse, ni siquiera a mediano plazo.

Una rápida mirada a algunos indicadores clave del desarrollo (ingreso per cápita, nivel y calidad del empleo, índices de pobreza, nutrición, mortalidad infantil, morbilidad, acceso a la educación formal, valor agregado de la producción, entre otros) evidencia un estancamiento, cuando no un retroceso continuo, desde inicios de la década de los ochenta, lo cual se ha traducido en una caída estrepitosa de la calidad de vida de amplios sectores de la población.

La Comisión Económica para América Latina publicó en 1990 un importante documento (CEPAL, 1990) donde planteaba la urgente necesidad de que Latinoamérica y el Caribe reencontrasen el camino del desarrollo. Esto determinaba una serie de exigencias de cara a la nueva realidad política y económica imperante en el ámbito internacional. Entre otras cosas, las diferentes naciones de la región debían contemplar en su agenda política el fortalecimiento de la democracia, la estabilización y ajuste estructural de sus economías y la incorporación de las mismas a una dinámica de cambio tecnológico intensificada como nunca a escala global. Además, debían procurar de forma imperativa una mejora sustancial de la distribución del ingreso, procesos que debían darse en un contexto ambientalmente sostenible.

Desde el punto de vista del desarrollo económico, los desafíos planteados resultaban complejos e innumerables. De manera general, en el estudio se planteaba la necesidad de impulsar modificaciones de carácter estructural que permitieran avanzar desde un modelo industrial consolidado alrededor de la renta perecible, producto de la explotación de los recursos naturales, hacia un modelo de renta dinámica basado en la incorporación del progreso técnico a la actividad productiva.

Por cuestiones del alcance del estudio, no entramos en consideraciones acerca de la viabilidad de la proposición de la CEPAL. No obstante, hay que advertir que las tendencias políticas imperantes en la región en ese momento, caracterizadas por una marcada liberalización, hacían difícil que muchos elementos de un proyecto de carácter normativo como ése, fueran considerados e incorporados en la agenda política de los gobiernos.

El desempeño social y económico que mostró la mayoría de los países de la región durante la década de los noventa, y la actual situación que confrontan, demuestran cuán poca atención se prestó a estas recomendaciones. Podría aseverarse que muchos de los desafíos planteados en dicho estudio en términos de mejorar la situación socioeconómica permanecen sin alteraciones y, en algunos casos, las condiciones de partida que se sugería modificar se agravaron. Si bien en la generalidad de los casos se consolidaron procesos políticos democráticos, y en la mayoría de las economías se logró la precaria estabilización de algunas variables macroeconómicas, esto no se tradujo en avances significativos desde el punto de vista social, área en la cual se produjeron, incluso, retrocesos importantes. 
En el ámbito productivo, la región experimentó cambios estructurales relacionados con variaciones importantes en la composición del capital en la mayoría de los sectores, traducidos en un debilitamiento de la participación del Estado y una creciente participación del capital extranjero. Por otra parte, se acentúa un importante desarrollo del sector servicios acompañado de un fortalecimiento de las actividades de extracción y transformación primaria que plantea interrogantes con relación a su sustentabilidad.

Los programas de estabilización y ajuste estructural tuvieron como eje central la liberación comercial, que fue quizás el principal instrumento de la globalización. Los programas de integración económica vienen realizando esfuerzos para estimar las incidencias de este proceso sobre el ambiente, tema que genera agudas polémicas. Algunos estudios sugieren que "el libre comercio ha acarreado mejoras en la calidad ambiental, en especial cuando obedece al intercambio de nuevas y más eficientes tecnologías de capital, el intercambio de prácticas de administración ambiental y otros factores. ${ }^{3} \mathrm{Al}$ tiempo, al libre comercio se le ha relacionado con la degradación ambiental". ${ }^{4}$

Si bien estos estudios no aportan resultados concluyentes acerca del efecto neto del comercio sobre el ambiente, no parecen plantear la existencia de asimetrías. En el caso de América Latina, donde la capacidad institucional en materia ambiental es débil, en muchos casos se registran impactos negativos de significación (Tockman, 2001; Borregaard y Bradley, 1999). De allí la legítima preocupación de amplios sectores con relación a este problema, que bien pudiera resumirse en la siguiente aseveración de Joseph Stiglitz (2002): "La globalización actual no funciona. Para muchos pobres de la tierra no está funcionando. Para buena parte del medio ambiente no funciona. Para la estabilidad de la economía global no funciona".

\section{La importancia de las politicas de competitividad en la transición de los paradigmas}

Se ha insistido en que uno de los grandes problemas de la agenda política de la mayoría de los gobiernos de la región durante los noventa, fue la atención casi exclusiva que se le prestó a los problemas en el área económica, más específicamente, a la esfera macroeconómica. Se pensaba que con la simple corrección de los graves desequilibrios existentes, en particular en los ámbitos fiscal, monetario y arancelario, se crearían las condiciones para retomar el crecimiento económico. Una excesiva confianza en los mecanismos de mercado dejaba en manos de éste la orientación de la actividad económica. De esta manera, se impulsaron agresivos procesos de apertura y desregulación, suponiendo que éstos genera-

Las cursivas son nuestras.

Estudios técnicos muestran "que las emisiones de SOx y NOx aumentan a la par del ingreso per cápita de un país, pero después de cierto nivel de ingreso su trayectoria aumenta mientras que la de emisiones sigue direc ción opuesta. Otros datos muestran que las emisiones de gases invernadero y la degradación del hábitat, parecen aumentar acompañando el crecimiento del PIB" (CCA, 2002). 
rían señales suficientemente claras a los diferentes actores económicos para adaptarse a una nueva realidad mundial caracterizada por ser mucho más competitiva. ${ }^{5}$

Desde el punto de vista industrial, estas agendas planteaban la necesidad de fortalecer aquellos sectores que fueran capaces de integrarse a la economía global. En otras palabras, se pretendía impulsar actividades productivas y de servicios con objeto de desarrollar una efectiva capacidad de competir y exportar, pero básicamente a través de la creación de condiciones macroeconómicas favorables y mecanismos de estímulo a la actividad exportadora (Suzigan y Villela, 1997). No obstante, instrumentos de promoción al desarrollo industrial e incentivos directos a la actividad tecnológica no fueron considerados importantes dentro de esta agenda política (Ávalos, 1993). De esta forma, es lógico suponer que resultaría muy difícil avanzar hacia un modelo de renta dinámica basado en la incorporación de progreso técnico a la actividad productiva.

Esta simplificación de las políticas económicas e industriales en los países de la región, se daba en un marco de crecientes transformaciones institucionales en los países desarrollados y una sorprendente tendencia a aumentar la complejidad de la actividad tecnoproductiva. Con relación al primer aspecto, es necesario señalar dos elementos que devendrían clave en el impulso y orientación de la actividad innovadora: el primero, un fortalecimiento de los espacios de política científica y tecnológica, caracterizado por un incremento de la acción de los Estados para impulsar una creciente y cada vez más costosa actividad de investigación y desarrollo (I\&D). Esto mediante la instrumentación de novedosos esquemas de estímulo y cooperación entre diferentes actores y organismos relacionados con la actividad: centros de investigación científica, centros de desarrollo tecnológico y empresas.

El segundo elemento, más ubicado en el ámbito privado, se relaciona con el surgimiento y difusión de principios y normas de actuación de adscripción voluntaria en el seno de algunas industrias y gremios empresariales. Los mismos procuran incrementar la calidad de los productos, mejorar y estandarizar los procesos de producción y tornar más compatibles las actividades industriales con el ambiente. Lo interesante es que estas proposiciones de carácter normativo se han venido desarrollando independientemente del marco regulatorio de los Estados y, más recientemente, han comenzado a coordinarse con algunos instrumentos de política pública.

Por su parte, la creciente complejidad de la actividad tecnoproductiva ha estado muy ligada a la implantación y difusión del nuevo paradigma tecnoeconómico basado en la microelectrónica y caracterizado por un uso intensivo de la información (Pérez, 1992). Quizá, el ejemplo más cotidiano y fehaciente de este proceso sea la extraordinaria difusión

Desafortunadamente, los mercados existentes en estos países eran sumamente deficientes, caracterizados por estructuras fuertemente oligopólicas y hasta monopólicas en sectores muy importantes. Lo paradójico es que después de todos estos años de aplicación de medidas de estabilización y ajuste estructural, que procuraban corregir esta situación, muchas de estas estructuras se han mantenido y en algunos casos se han intensificado. 
y uso de Internet, y el constante surgimiento de productos y servicios que se trasmiten por este medio, proceso que está modificando, incluso, los conceptos mismos de industria y comercio.

Sin duda, estos dos factores han contribuido decisivamente a las profundas transformaciones que han experimentado infinidad de sectores productivos (cambios importantes en la concepción de los productos y de los procesos). La ampliación de las posibilidades de manejo y control de la producción inherentes a la microelectrónica y a la informática en las áreas de la hoy llamada vieja economía, es decir, todas las industrias y servicios fuera del ámbito de las nuevas tecnologías, resultan elementos clave en el desarrollo de técnicas de mitigación y prevención del impacto ambiental de sus actividades. Puede señalarse que la microelectrónica y la informática constituyen parte fundamental de la base técnica que está posibilitando el desarrollo de procesos productivos más limpios que, en general, producen un menor impacto ambiental.

También puede decirse que el "nuevo sentido común" (Pérez, 1992) está siendo moldeado por elementos socioculturales mucho más allá de las intensas modificaciones generadas socialmente por la irrupción de las nuevas tecnologías —en especial la microelectrónica-. Y justo aquí surge uno de los aspectos más interesantes del proceso de transformación en marcha: la necesidad de mitigar y evitar el impacto de las actividades humanas sobre el ambiente y el imperativo de avanzar hacia modelos de desarrollo sustentables están siendo determinados cada vez más por elementos de carácter ético y político (Höhn, 1997), los cuales emergen como factores decisivos en la conformación de un nuevo paradigma.

Así, la transición iniciada en los años setenta — desde un modelo productivo basado en el uso intensivo de materias primas y energía a uno basado en el uso intensivo del conocimiento, el cual lleva implícita la disminución del impacto ambiental—, ${ }^{6}$ comienza a tornar explícita la condición de la sustentabilidad. Esto lleva a pensar en la posibilidad de estar ante una transición que va más allá de un cambio de paradigma tecnoeconómico, pues cabría considerar la posible emergencia de un nuevo modelo de desarrollo. Así, tendría que avizorarse el proceso como una transición entre paradigmas, desde una perspectiva fundamentalmente tecnoeconómica a una productiva-ambiental. ${ }^{7}$ Algunos de los elementos que incorpora el "nuevo sentido común" se enumeran a continuación:

6 La creciente desmaterialización de la producción y la miniaturización de los productos y la tecnología, han producido un desacoplamiento progresivo entre el incremento del producto bruto y el consumo de recursos materiales y energéticos en los países desarrollados (Simonis, 1997).

$7 \quad$ La discusión acerca de si la noción de cambio de paradigma tecnoeconómico (Pérez, 1998) engloba la pers pectiva productiva ambiental como una de las formas que adopta la actual transición, excede el alcance de este trabajo. Sin embargo, cabe mencionar que una de las contribuciones fundamentales que podría aportar el concepto de paradigma productivo ambiental es la inclusión, de manera explícita, de la dimensión política y la participación de diversos actores sociales en su conformación.

Algunos autores, intentando destacar las profundas transformaciones culturales en marcha, van más allá en la generalización y definen los cambios en el ámbito del "paradigma social" (Capra, 1998), el cual 
- Competitividad entendida dentro de límites del uso sustentable de los recursos naturales.

- Producción concebida racionalmente en la perspectiva del ciclo de vida de los productos.

- Percepción ética del consumo (interés por conocer las formas de producción y sus impactos socioambientales).

- Participación política más amplia en las decisiones de la producción (incorporación de nuevos actores en la definición de la agenda política de producción y comercio).

\section{El desarrollo sustentable}

La Comisión Mundial del Ambiente y Desarrollo definió el desarrollo sustentable como aquél que permite a la generación actual satisfacer sus necesidades sin poner en peligro la capacidad de las futuras generaciones de satisfacer sus necesidades propias (World Commission on Environment and Development, 1987). A partir de este difuso pero significativo concepto se vienen haciendo planteamientos que insisten en la necesidad de modificar el patrón de desarrollo imperante. Para muchos es imposible seguir reproduciendo un modelo de desarrollo fundamentado en la creencia del progreso material ilimitado a través del crecimiento económico y el desarrollo tecnológico (Capra, 1998).

Modificar los patrones de desarrollo implica transformaciones radicales en los sistemas productivos, lo cual implica, a su vez, cambios estructurales importantes en las esferas política y económica. De alguna manera se plantea que los imperativos del desarrollo deben establecerse tomando en cuenta factores que vayan mucho más allá de los criterios de racionalidad económica, en particular, se debe hacer una consideración especial de los imperativos de carácter ecológico. ${ }^{8}$

Todo lo anterior evidencia que se está avanzando en un proceso de cambio de la estructura sociotécnica a escala global. Ahora bien, ¿hasta qué punto, y a qué ritmo están sucediendo estas transformaciones productivas en América Latina? O, dicho de otra manera, ¿qué perfil se está configurando en las estructuras tecnoproductivas de los países de la región, en medio de la difusión del nuevo paradigma productivo ambiental basado en el uso intensivo de la información?

\section{América Latina: ¿transformación productiva sustentable?}

Los años noventa trajeron consigo el retiro del Estado no sólo de la actividad productiva, sino de las actividades de promoción y apoyo directo a su desarrollo. La severa crisis

consiste en "una constelación de conceptos, valores, percepciones y prácticas compartidos por una comunidad, que conforma una particular visión de la realidad que, a su vez, es la base del modo en que dicha comuni dad se organiza".

8 Entendiendo el término ecológico en la perspectiva amplia que "reconoce la interdependencia entre todos los fenómenos e implica el hecho de que, como individuos y sociedades, estamos inmersos en (y finalmente dependientes de) los procesos cíclicos de la naturaleza" (Capra, 1998). 
económica de los ochenta llevó a un fuerte cuestionamiento de los esquemas de política industrial adoptados en el marco de la sustitución de importaciones.

No obstante, son pocas las personas que se atreven a negar que desde inicios de los años cincuenta hasta finales de los setenta, Latinoamérica demostró significativos avances no sólo en función del desarrollo económico, sino social. A pesar de ello, se condenó de manera generalizada el papel promotor y regulador del Estado, elemento clave de este desempeño.

Desde el punto de vista económico, el periodo que va desde los inicios de los años cincuenta hasta inicios de los ochenta, demostró un balance muy positivo; el aspecto más destacado fue el rápido proceso de industrialización que se experimentó en diversos países de la región, en especial en los grandes y medianos. La política de industrialización por sustitución de importaciones (ISI), permitió la implantación y consolidación de diversas ramas industriales. El perfil general de la industrialización implicó, en un primer momento, la conformación de diversas ramas productoras de bienes finales, lo cual corrió por cuenta de filiales multinacionales y algunas empresas nacionales emergentes. Casi simultáneamente, se dio inicio al desarrollo de industria pesada ligada a algunas actividades de transformación primaria (siderurgia y petroquímica, principalmente), que contó, generalmente, con una importante participación del Estado.

Si bien las empresas multinacionales tuvieron un papel decisivo en las primeras etapas de la industrialización, la política de sustitución de importaciones abrió importantes espacios para el surgimiento de empresas privadas nacionales y mixtas. Cabe señalar que, en buen número de casos, estas firmas alcanzaron importantes niveles de desarrollo tecnoproductivo, mediante sostenidos procesos de aprendizaje tecnológico (Pirela, 1996; Mercado, 2000), constituyéndose, algunas de ellas, en importantes motores de la innovación tecnológica de la región. ${ }^{9}$

Sin dejar de reconocer las grandes distorsiones que tuvo el modelo de sustitución de importaciones - caracterizado entre otras cosas por un excesivo proteccionismo y una mala distribución y utilización de los recursos destinados a la promoción de la actividad industrial-, éste coadyuvó a un sólido crecimiento económico durante estos años y, lo más importante, un buen porcentaje de este crecimiento correspondía a la agregación de valor nacional a la producción. Esto determinó una creciente demanda de empleo, con las consecuentes necesidades de capacitación de recursos humanos, y posibilitó, además, la generación de excedentes que estimulaban la reinversión, ampliación y diversificación de las actividades productivas.

9 En un estudio realizado por el programa Ciencia y Tecnología para el Desarrollo sobre 100 empresas innovadoras en América Latina (CYTED, 1992), la muestra quedó conformada por 80 grandes empresas privadas nacionales, 4 públicas, 12 joint ventures (mixtas) y 4 extranjeras. Lo anterior es un indicativo de los niveles de capacitación que alcanzaron algunas de las nacionales. 
Estas posibilidades de generación de bienes tangibles aunadas al impacto de los programas del Estado en las áreas de educación y salud contribuyeron, de modo general, a una elevación de la calidad de vida de la población. Al parecer, éstos eran algunos de los elementos que tenían en mente los investigadores de la CEPAL, coordinados por Fernando Fajnzylber, cuando en 1990 plantean la urgente necesidad de que los países de América Latina y el Caribe reencontraran el camino del desarrollo.

La irrupción de la crisis económica a inicios de los ochenta presentó, entre otras consecuencias, la disminución importante de la inversión pública y privada. Así, por ejemplo, la inversión en infraestructura disminuyó considerablemente durante esa década (Suzigan y Villela, 1997). De igual forma, se evidenció un retroceso en los niveles de inversión en ciencia y tecnología y en educación superior. Esto contribuyó, por una parte, a debilitar la base de conocimiento de una estructura tecnoproductiva que, en el caso de diversos sectores, aún se encontraba en ciernes; y, por otra parte, a la disminución de los esfuerzos de aprendizaje tecnológico adelantados por muchas empresas hasta entonces (Pirela, 1996; Mercado, 1995).

A finales de los ochenta se da un giro a la política económica en la mayoría de los países, poniendo el énfasis en la esfera macroeconómica. Esto implicó un cambio de orientación muy fuerte, destinado a la creación de condiciones estructurales de competitividad, pero sin prestar atención al apoyo directo para el desarrollo de las capacidades tecnológicas. ${ }^{10}$ Ello contribuyó a debilitar aún más la capacidad tecnológica de diversos sectores industriales, en especial la de muchas empresas de capital nacional, construida durante los más de cuarenta años precedentes.

Diversos estudios sobre política industrial y reformas macroeconómicas, implantadas en América Latina y otras regiones, han reconocido el impacto negativo que tuvieron la mayoría de estos programas sobre la estructura industrial, especialmente en las etapas iniciales de implantación del ajuste estructural (Baruk, 1997; Peres, 1993). Los técnicos encargados de llevar adelante los programas estimaban que las empresas reaccionarían favorablemente y, una vez superada esta etapa inicial, las estructuras productivas entrarían en un proceso de crecimiento sostenido mediante un esfuerzo por incrementar sus capacidades competitivas que se traduciría en un aumento de su capacidad exportadora (Naim, 1993).

Ahora bien, ¿hasta qué punto estos intentos de modernización tomaron en consideración las transformaciones tecnológicas e institucionales que estaban ocurriendo a escala mundial?, ¿se consideraba en sus agendas, como lo hacían los países en desarrollo, la adopción de medidas para fortalecer los espacios institucionales de la ciencia y la tecnolo-

10 En ese momento, se comienzan a introducir cambios socioinstitucionales que a la postre determinarían profundos cambios en la dinámica tecnoproductiva de diversos sectores industriales. Las drásticas modificaciones en la política comercial iniciada en los noventa y, más recientemente, en la política de propiedad industrial, definieron un escenario radicalmente distinto para la actividad productiva. 
gía? O, de manera más general, ¿se proponían políticas explícitas para que las estructuras productivas pudieran afrontar con éxito los desafíos que planteaba la irrupción del nuevo paradigma productivo-ambiental?

La marcada concentración de la atención en los problemas macro de la economía, no permitió una consideración explícita de estas importantes variables de la nueva realidad tecnoproductiva. Se delegaba en las empresas la responsabilidad de afrontar las profundas transformaciones del entorno económico que avanzaba rápidamente hacia la apertura y la desregulación, a lo cual se agregaba el deber de afrontar la situación de incertidumbre que caracteriza la transición tecnoproductiva que se viene dando a escala mundial.

Transcurrida más de una década de los intentos de modernización económica, es conveniente hacer una revisión de la evolución de algunos indicadores económicos, más específicamente de carácter productivo, para determinar si efectivamente sucedieron las tan afanosamente procuradas transformaciones estructurales. Ello permitirá inferir, además, si realmente se está conformando un nuevo perfil productivo más en sintonía con las tendencias en materia tecnológica y ambiental presentes en el nuevo paradigma emergente.

\section{Evolución de la estructura productiva de la región}

El análisis de algunos indicadores económicos sirve para mostrar las tendencias de cambio estructural en los sectores productivos de los países de la región. En primer lugar, se analiza la evolución del producto interno bruto (PIB) para determinar si se logró entrar en una fase de crecimiento continuo, tal como se esperaba que ocurriría después de la aplicación de los programas de estabilización y ajuste. En segundo lugar, se presenta la evolución sectorial del producto industrial a fin de estimar en qué actividades se ha sustentado con mayor firmeza el crecimiento económico de los últimos años y determinar, de manera general, hasta qué punto se está configurando o no, un modelo productivo ambientalmente sustentable. ${ }^{11}$ Por último, se analiza la composición de las exportaciones con la finalidad de estimar el perfil de inserción de la estructura productiva de los países de la región en el ámbito internacional.

\section{Evolución del PIB}

Después de los severos tropiezos sufridos durante la década de los ochenta, América Latina comenzó a experimentar índices positivos de crecimiento económico durante la década de los noventa. No obstante, éste demostró un comportamiento errático en dos ciclos

11 La posibilidad de caracterizar el desempeño ambiental de la estructura productiva en América Latina requiere de estudios detallados en los niveles micro y mesoeconómico, así como el desarrollo de metodologías de evaluación que tomen en cuenta tanto las especificidades sectoriales como las particularidades de la región, especialmente en lo que se refiere a las dificultades para obtener información (Mercado y Testa, 2001). Sin embargo, resulta sugerente que utilizando datos muy agregados sea claramente perceptible una serie de tendencias que parecen ir en dirección contraria al desarrollo sustentable en Latinaoamérica. 


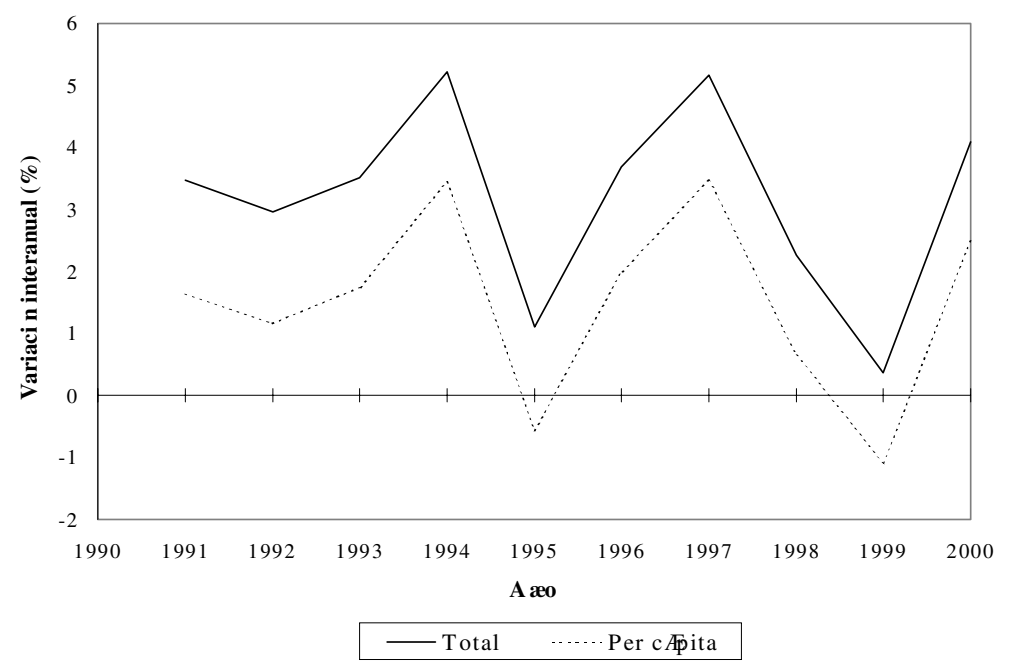

Gráfica 1. Variación interanual del producto interno bruto (PIB) en América Latina. Fuente: CEPAL. ${ }^{12}$

importantes (1991-1994 y 1996-1997), interrumpidos por dos abruptas desaceleraciones: la de 1995, desencadenada por la crisis mexicana y en 1998-1999, derivada de la crisis financiera del sudeste asiático, que golpeó severamente algunas de las principales economías de la región (Brasil, Argentina y Chile, en particular). Adicionalmente, la profunda inestabilidad política y social de naciones como Venezuela, Ecuador, Perú y Colombia — debida en gran medida a la aplicación de los programas de ajuste-, afectaron negativamente el desempeño a lo largo de este período (véase Gráfica 1). ${ }^{13}$ Los datos revelan la gran vulnerabilidad que continúan presentando las economías de la región en el escenario internacional. Si bien muchos países consiguieron estabilizar sus atribuladas economías durante los años noventa, dicha estabilidad ha demostrado ser, en la mayoría de los casos, muy precaria, y los programas adoptados poco eficientes en la corrección de importantes factores de carácter estructural. En consecuencia, la irrupción de crisis financieras en alguno de los países importantes de la región, o en otras latitudes, desata y pone al descubierto nuevamente serios problemas económicos que conducen a la aplicación de nuevos ajustes. Esto lleva a la conformación de un círculo vicioso, pues a cada irrupción cíclica de la crisis sigue irremediablemente un nuevo ajuste económico, el cual tiene incidencias cada vez más negativas sobre la ya deteriorada situación social y ambiental.

La vulnerabilidad de las economías de la región se ha asociado históricamente al marcado peso que han tenido las materias primas y los productos semielaborados en las exportaciones, y es así porque las intensas variaciones cíclicas de los precios de estos productos

12 Las fuentes de éste y las siguientes gráficas, así como de la Tabla 1, hacen referencia a diversos años (1974 2001) del Anuario estadístico de América Latina y el Caribe.

13 El derrumbe de la economía argentina a finales de 2001 y la amenaza de estallido de una nueva crisis en Brasil configuran un escenario donde ya no es posible esperar una fase de crecimiento continuo. 
pueden interrumpir, abruptamente, los periodos de crecimiento. Por otra parte, hay que señalar que en el último decenio los precios de casi todas las materias primas y los productos primarios experimentaron una marcada depresión que alcanzó, en muchos casos, mínimos históricos.

Asimismo, la variación del PIB per cápita muestra que la relación crecimiento económico/ crecimiento poblacional no registra modificaciones importantes en el ingreso de la mayoría de la población. De hecho, el crecimiento del PIB per cápita para 1995 se colocaba en niveles inferiores a los registrados en 1980 (Arocena, 1997), situación preocupante, sobre todo, si tomamos en cuenta las tendencias de mantenimiento de altas tasas de natalidad, incremento del desempleo y concentración de la riqueza que se experimentaron en los últimos años. ${ }^{14}$

Lo anterior evidencia limitaciones serias del modelo económico. Podría argumentarse que algunos de estos problemas son inherentes a la implantación del nuevo paradigma tecnoeconómico —el aumento del desempleo estructural tecnológico, por ejemplo—. Sin embargo, éste no parece ser el caso de la región, pues el principal impacto sobre el mercado de trabajo se ha dado fundamentalmente por los efectos recesivos de las políticas de ajuste económico, ${ }^{15}$ y sólo en los últimos años ha comenzado a actuar parcialmente sobre él el proceso de modernización tecnológica (Lacabana y Mercado, 1997).

Un factor determinante de la expansión de la economía de la región durante los años noventa fue el extraordinario incremento de la inversión extranjera que pasó de 8,400 millones de dólares en 1990 a 63,400 millones en 1998, ¡un impresionante incremento de casi ocho veces! Los grandes flujos de inversión, sobre todo en los últimos años, se orientaron a los países más grandes, en especial a México y Brasil. Este último, en particular, concentró más de 30\% de las inversiones durante 1997 y cerca de 50\% en 1998. Sin embargo, a partir de 2001 se ha comenzado a experimentar una caída significativa de las mismas.

El mayor porcentaje de inversión extranjera directa correspondió a la privatización de importantes activos de los Estados, proceso muy intenso durante los primeros cuatro años de la década. Esta tendencia se modificó parcialmente en el bienio 1995-1996, periodo en el que se perciben importantes ingresos para nuevos proyectos de inversión, la reestructuración de las empresas privatizadas en los años precedentes y la adquisición de empresas privadas nacionales. ${ }^{16}$ A partir de 1997, se retoma la tendencia de transferencia de activos

14 En el informe del BID publicado el 8 de mayo de 2000, se muestran abiertamente los pocos avances relativos experimentados en el ingreso per cápita de la población, pues hace cincuenta años, éste sólo era superado por los países desarrollados, mientras que en la actualidad cayó al quinto lugar, por encima de África y algunas regiones de Asia. Por otra parte, la brecha entre ricos y pobres aumentó en la región a una tasa muy superior la del resto del planeta (Diario Economía Hoy, 9 de mayo de 2000).

15 Según datos de la CEPAL, en el año 2000, siete de cada diez puestos de trabajo en Latinoamérica se ubicaban en el sector informal, caracterizado por la desregulación y, en la mayoría de los casos, por la precarización (Diario Economía Hoy, abril de 2000).

16 Sólo en Brasil la adquisición de activos privados nacionales por parte de inversionistas extranjeros ascendió a 3,200 millones de dólares en 1997 (CEPAL, 1999). 
públicos al capital extranjero, en particular en Brasil y Colombia, pero se acentúa en toda la región la transferencia de activos privados nacionales, sobre todo en el área de manufactura, al control de empresas extranjeras (CEPAL, 1998).

Durante el primer periodo la mayoría de las adquisiciones se concentró en el sector servicios (telecomunicaciones, servicios financieros, líneas aéreas) y empresas de manufactura (en especial en Argentina, Brasil y Venezuela). El extraordinario repunte de la inversión extranjera observado a partir de 1997 obedeció a la conjunción de tres importantes factores: la privatización de las empresas del área de telecomunicaciones y los servicios de distribución de electricidad en Brasil y de grandes empresas mineras y petrolíferas, donde destaca la venta de Yacimientos Petrolíferos Fiscales en Argentina, la apertura petrolera en Venezuela y Brasil y la mayor apertura de nuevas áreas de servicios como la telefonía celular (CEPAL, 1999).

Un análisis de nuevas inversiones directas (proyectos nuevos o ampliaciones de proyectos existentes) muestra que, con excepción de México y en menor medida Brasil, la región está recibiendo importante cantidad de recursos orientados a las áreas de servicios (tradicionales y nuevos) y a las actividades primarias (minería y petróleo). En el caso mexicano las inversiones se concentran especialmente en diferentes áreas de manufactura (automotriz, computación y electrónica, química y farmacéutica, textiles y alimentos), a tal punto que, para el periodo 1997-2001 éstas correspondían aproximadamente a dos tercios del total. En el caso brasileño, si bien se registra un alto porcentaje de ingresos para servicios, también hay una inversión importante en manufactura, alcanzando ésta un poco más de un tercio del total. Esta tendencia desigual, como se verá a continuación, está incidiendo en la configuración de determinados patrones de desarrollo productivo y formas particulares de inserción en la economía internacional (CEPAL, 1998).

\section{Evolución sectorial del PIB}

Para analizar estos aspectos se realiza, en primer lugar, una revisión de la variación interanual del producto interno bruto de las grandes ramas de actividad económica consideradas por la CEPAL, a saber: agricultura, minas y canteras (incluye la explotación petrolera), manufactura (incluye las diferentes actividades de transformación), construcción y servicios básicos, la Gráfica 2 presenta las tendencias para el periodo 1970-2000.

Las líneas evidencian un comportamiento dual respecto a las tendencias de estructuración de la actividad económica que se vienen dando en los países desarrollados de cara al surgimiento del nuevo paradigma productivo-ambiental. Este comportamiento se caracteriza por:

1) Un acoplamiento respecto a las tendencias de los países desarrollados traducido en América Latina en una creciente participación del sector terciario de la economía (pendiente positiva de la línea del sector servicios) en la conformación del PIB. 


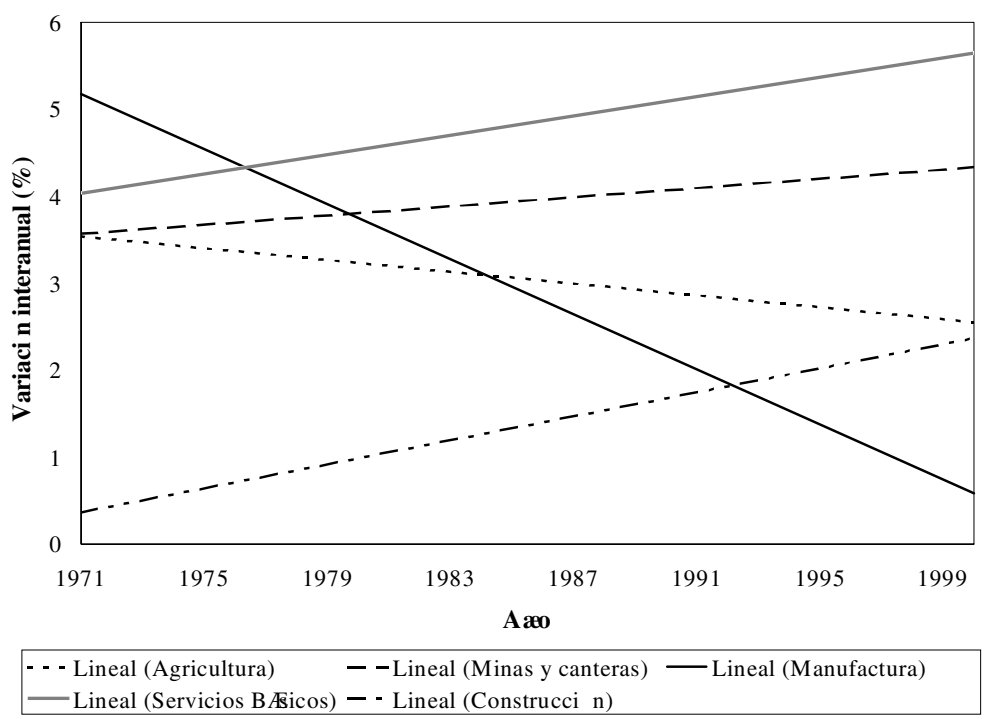

Gráfica 2. Evolución tendencial del producto bruto por sectores económicos en América Latina.

Fuente CEPAL.

2) Un desacoplamiento respecto a las tendencias globales, caracterizado en América Latina por el crecimiento continuo del producto bruto de las actividades de explotación de recursos naturales; en el caso de minas y canteras se observa una pendiente positiva. ${ }^{17}$

3) Un desacoplamiento respecto a las tendencias globales en la actividad industrial, caracterizado en América Latina por una desaceleración significativa del crecimiento del producto bruto de las actividades de manufactura. Nótese que esta línea presenta la pendiente más negativa de todas las ramas de actividad económica.

4) Un desacoplamiento respecto a las tendencias de los países desarrollados en las actividades agropecuarias. Si bien en este caso la tendencia de crecimiento de esta rama de actividad económica en los países desarrollados también es negativa, las diferencias derivan del tipo de actividad, traducido en el caso de los países en desarrollo en una explotación intensiva de recursos primarios (bosques originales) y una apertura indiscriminada de los mercados, acompañada de la eliminación de subsidios a los productores.

Estos resultados permiten advertir que el perfil productivo que se está conformando en la región, apunta hacia una inserción complementaria de la economía regional en la economía global que difiere muy poco de la tradicional —incluso se acentúan algunos rasgos del perfil primario exportador-. Así, a diferencia de los países desarrollados, los cuales

17 Hay que destacar que durante la última década, Latinoamérica captó más de la tercera parte de las inversiones mundiales en esa área (Arocena, 1997). 


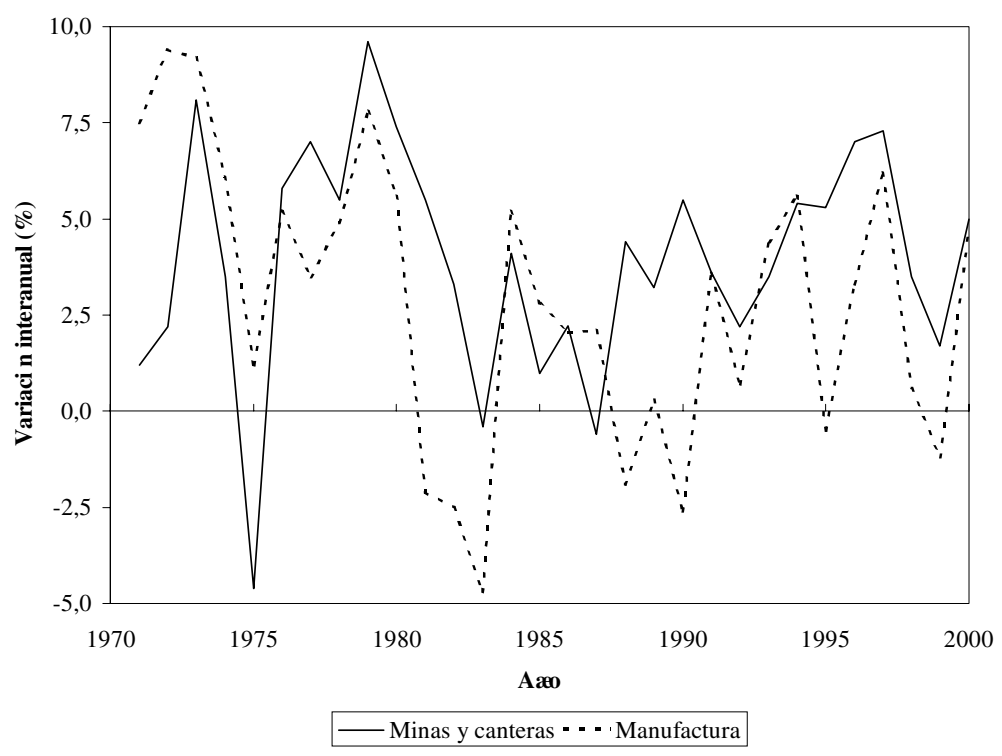

Gráfica 3. Variación interanual del producto bruto por sectores económicos en América Latina.

Fuente: CEPAL.

fundamentan buena parte de su crecimiento en actividades de manufactura, especialmente en aquellas vinculadas al desarrollo de las tecnologías de punta, América Latina parece consolidar su modelo productivo apoyada fuertemente en la explotación de recursos naturales, actividades industriales pesadas inherentes a la vieja economía y en las actividades de servicios. Algunos autores señalan, incluso, que se está avanzando hacia una "reprimarización” de la actividad económica (Lacabana, 1999).

Sin duda, esta especialización tiene implicaciones importantes en función de la sustentabilidad de la actividad productiva. En primer lugar, el crecimiento sostenido del producto bruto de las actividades extractivas (minas y canteras) (véase Gráfica 3) y el incremento sostenido de las exportaciones en la mayoría de estos rubros sugieren la existencia de inmensas presiones sobre el ambiente, bien sean consecuencia de la explotación intensiva de los recursos naturales o por el potencial de generación de impactos ambientales inherentes a los procesos de extracción. ${ }^{18}$

Los riesgos de una explotación intensiva de los recursos naturales, se relacionan con su agotamiento, o con inadecuados manejos de su explotación. Por citar sólo dos ejemplos, tenemos el caso de la explotación indiscriminada de los bosques en Chile durante los años ochenta, la cual causó severos daños al medio por la destrucción de bosques naturales que,

18 Organizaciones no gubernamentales, como Amigos de la Tierra, indican que la exportación de recursos naturales ha aumentado en forma asombrosa en países que aplican ajustes recomendados por el Fondo Monetario Internacional sin haber tomado en cuenta la sustentabilidad de ese modelo. 
en algunos casos, afectaron severamente algunas especies autóctonas (Messner et al., 1992), o la explotación a máxima capacidad de producción de los pozos petroleros en Venezuela durante el periodo 1997-1998, lo cual ocasionó daños ambientales de consideración. En este caso, no sólo se vio afectada la seguridad y el riesgo operacional de los pozos, sino que la intensa actividad de explotación y perforación implicó la ocurrencia de una cantidad apreciable de accidentes y la generación de grandes cantidades de desechos (en especial lodo de perforación) que tuvieron un importante impacto ambiental (Diario El Universal, 25 de julio de 1998). Por otra parte, diversas agrupaciones ambientalistas estiman que más de la mitad de las áreas boscosas fronterizas de América del Sur se encuentran amenazadas por las actividades de un creciente número de proyectos de explotación minera (Diario Economía Hoy, abril de 2000).

Como se mencionó, la explotación de los recursos naturales en América Latina, en la última década, se dio en condiciones de mercado muy desfavorables. La significativa disminución de las cotizaciones de las materias primas y productos primarios que, como en el caso del petróleo en 1998, alcanzaron niveles próximos a los costos de producción, implican severos problemas para el ambiente, pues la necesidad de mantener márgenes mínimos de rentabilidad de la actividad lleva muchas veces a recortes de gasto que pueden implicar una disminución de la preocupación por los planes de contingencia y preservación ambiental.

Lo anterior muestra que se está configurando un panorama productivo muy complejo en términos de sustentabilidad. La disminución de los índices de crecimiento de la manufactura y el incremento de los índices de los sectores de extracción y explotación de materias primas, con precios históricamente bajos, configuran un escenario poco propicio para la preocupación y la protección social y ambiental. Un escenario que a todas luces es insostenible en el mediano plazo.

\section{Composición de las exportaciones}

Se analizó la evolución y la composición de las exportaciones (participación de productos manufacturados vs. materias primas) de los seis países más importantes desde el punto de vista de producción industrial, con el objetivo de establecer si, efectivamente, se está avanzando en la conformación de un perfil productivo más acorde con los principios de sustentabilidad presentes en el paradigma productivo-ambiental emergente.

Uno de los objetivos de las reformas macroeconómicas, introducidas desde finales de los ochenta en los diferentes países de la región, era fortalecer aquellos sectores que fueran capaces de desarrollar una efectiva capacidad de competir y exportar. Un análisis de la evolución de los montos de las exportaciones demuestra que, en términos absolutos, esto se cumplió de manera satisfactoria, pues entre 1980 y 2000 casi se cuadruplicaron (véase Gráfica 4). 


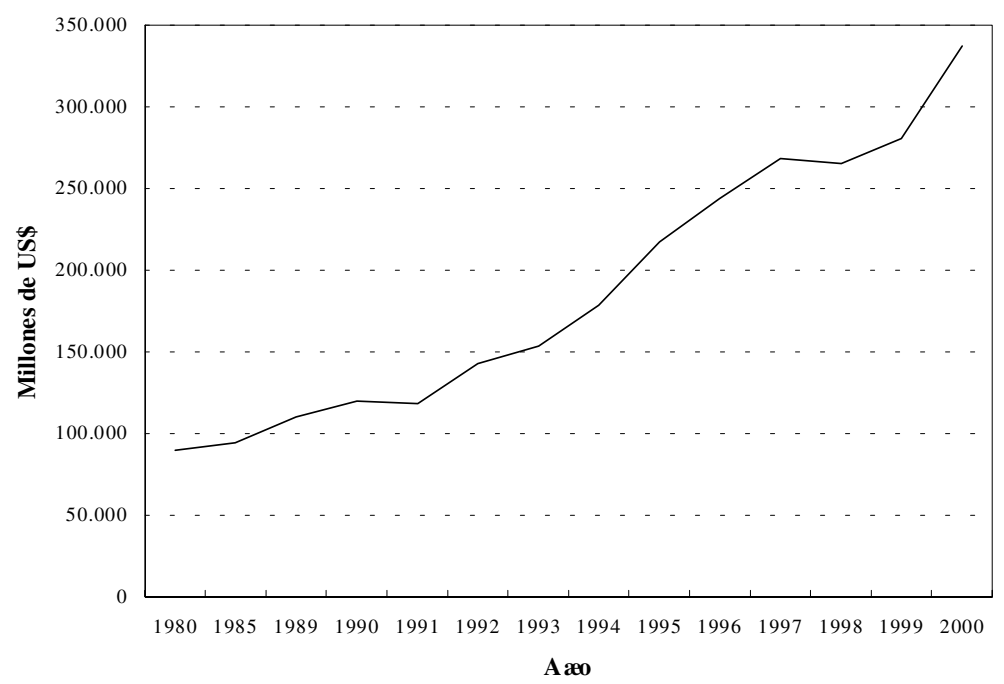

Gráfica 4. Exportaciones de América Latina.

Fuente: CEPAL.

Tabla 1

Exportaciones totales de los seis países más importantes de la región (millones de US\$)

\begin{tabular}{lrrrrrrrr}
\hline \multicolumn{1}{c}{ País } & 1993 & 1994 & 1995 & 1996 & 1997 & 1998 & 1999 & 2000 \\
\hline Argentina & 15,200 & 18,361 & 23,888 & 27,113 & 30,340 & 31,087 & 27,764 & 30,828 \\
Brasil & 42,765 & 48,025 & 51,819 & 54,254 & 59,100 & 59,037 & 55,205 & 64,470 \\
Chile & 11,532 & 14,461 & 19,927 & 18,711 & 20,772 & 18,948 & 19,406 & 22,087 \\
Colombia & 9,516 & 11,200 & 13,744 & 14,511 & 14,220 & 13,408 & 13,871 & 15,608 \\
México & 53,063 & 62,242 & 82,907 & 106,700 & 121,831 & 129,982 & 148,083 & 180,136 \\
Venezuela & 16,128 & 17,805 & 20,743 & 24,465 & 25,120 & 19,037 & 22,122 & 35,239 \\
\hline
\end{tabular}

Fuente: Cálculos propios a partir de CEPAL.

Los países de la Asociación Latinoamericana de Integración (ALADI) respondieron por más de $80 \%$ de las exportaciones totales de la región durante la década de los noventa y, dentro de ellos, las seis economías más importantes (Argentina, Brasil, Colombia, Chile, México y Venezuela) aportaron más de las tres cuartas partes del total (véase Tabla 1).

Un análisis más exhaustivo revela que México y Brasil, en correspondencia con el hecho de ser las economías más grandes y con mayores niveles de integración productiva, reportan los volúmenes más altos de exportación, muy superior al de los restantes cuatro países. Sin embargo, hay que destacar que México es el único país que ha incrementado de manera significativa sus exportaciones, triplicándolas en el periodo 1993-1999. Entre 1993 y 1996 se experimenta una sorprendente estabilización de la contribución de estos rubros a las exportaciones totales (en torno a 50\%), mostrando que, con excepción dec México, la vertiginosa expansión de la actividad exportadora en la región se ha consolida- 


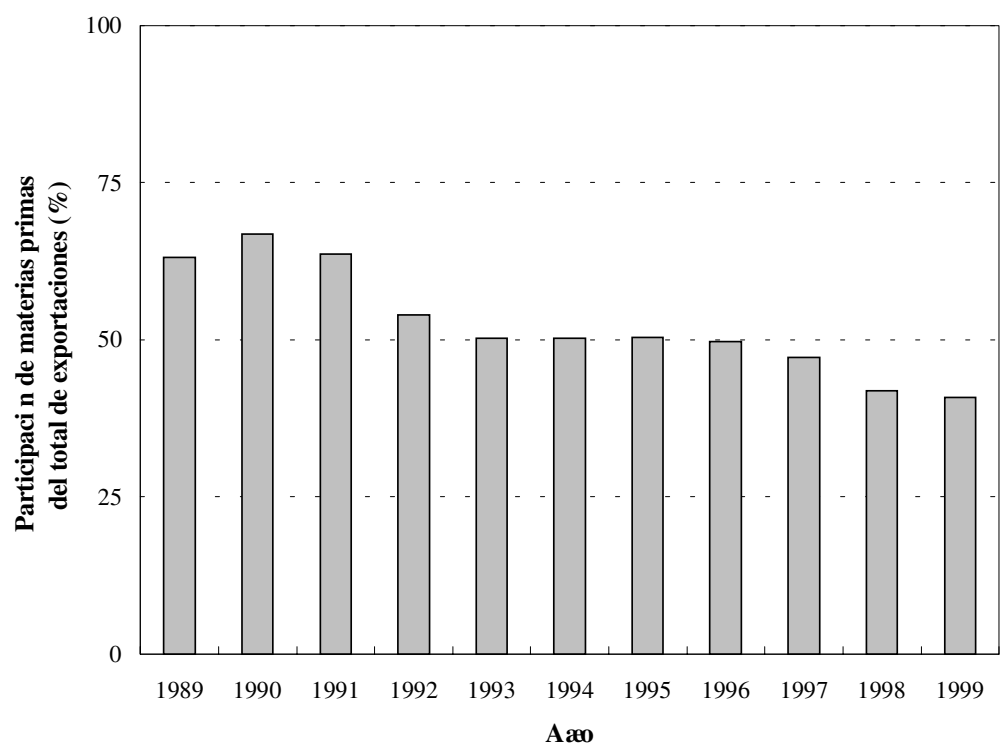

Gráfica 5. Participación de las materias primas en las exportaciones de Latinoamérica. Fuente: CEPAL.

do, en buena medida, por la tendencia expansiva de la transacción de bienes pertenecientes a los sectores primarios de la actividad económica. Desde 1997, se produce una nueva disminución de la participación de las materias primas en las exportaciones, situación que, como se verá a continuación, es debida, de manera casi exclusiva, al dinamismo mostrado por el sector manufacturero mexicano (véase Gráfica 5).

En segundo lugar, se produce una progresiva diferencia en el modelo de especialización del comercio exterior. En el caso de los países más grandes (Argentina, Brasil y México), se observa que sólo México y Brasil presentan una composición en la que las exportaciones de manufacturas están por encima de las de materias primas a lo largo del periodo considerado, mientras que en el caso argentino, éstas constituyen poco más de un tercio de las exportaciones totales (véase Gráfica 6). No obstante, hay que destacar que México fue el único país que experimentó cambios sustanciales en la composición de sus exportaciones, pues a partir de 1992 revierte la tendencia primaria exportadora y pasa a convertirse en un país fundamentalmente exportador de manufacturas, y ya para 1997 este sector respondía por más de $80 \%$ de sus exportaciones. En el caso de Brasil y Argentina, no se observan cambios importantes en la composición de sus exportaciones, y si bien entre los años 1991 y 1993 tendieron a incrementar la participación de la manufactura, para 1997 mostraban composiciones muy similares a las observadas a finales de la década de los ochenta.

En el caso de las tres economías más pequeñas (Colombia, Chile y Venezuela), es fácil advertir el marcado peso que continúan manteniendo las materias primas en las exporta- 


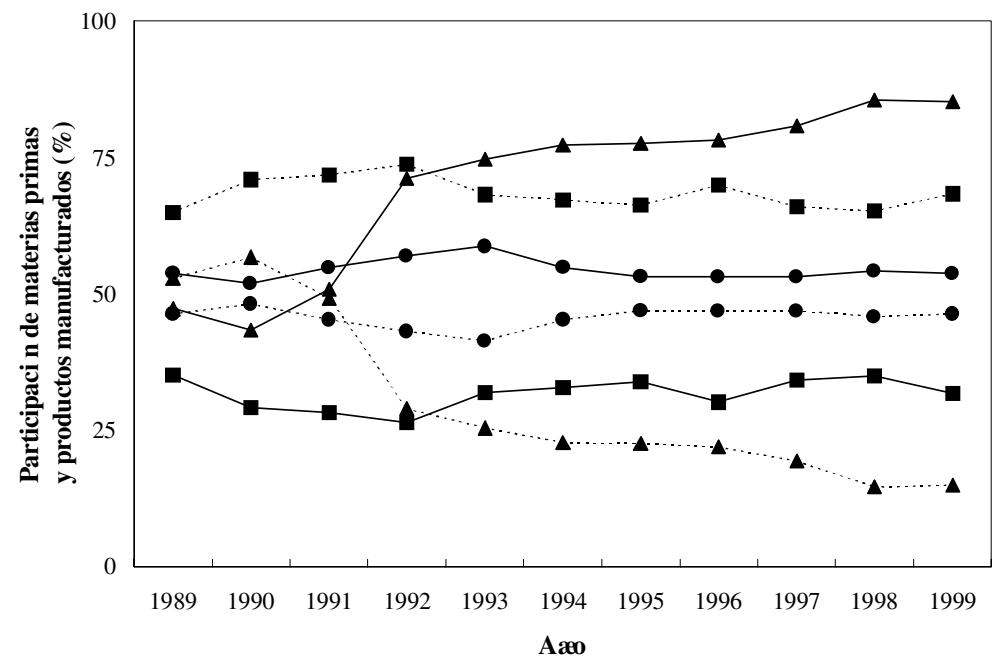

\begin{tabular}{lllll}
\hline$-\cdots$ & M. prima Brasil & - & Manufactura Brasil & $\cdots$ \\
$\rightarrow-$ Manufactura Argentina & $\cdots$ & . & M. prima Argentina \\
\hdashline & M. prima México & - & Manufactura México
\end{tabular}

Gráfica 6. Composición de las exportaciones de Argentina, Brasil y México. Fuente: CEPAL.

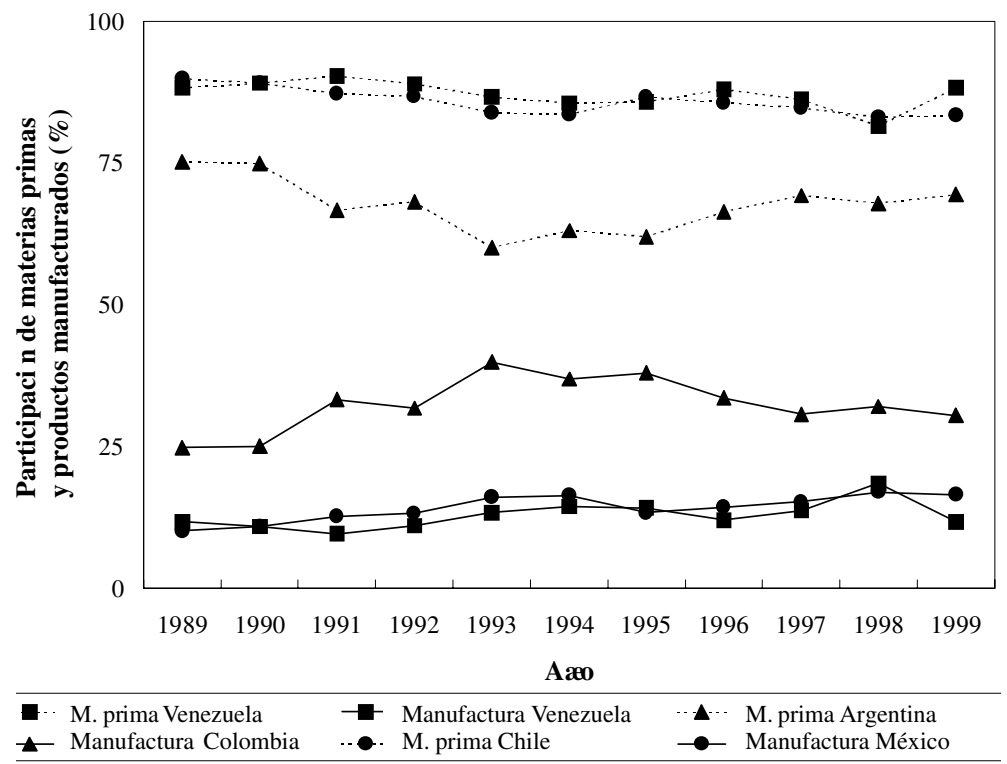

Gráfica 7. Composición de las exportaciones de Colombia, Chile y Venezuela. Fuente: CEPAL.

ciones (véase Gráfica 7). En estos casos, llama la atención la gran semejanza que muestra el desempeño de Chile y Venezuela, pues mantienen un perfil fundamentalmente primario exportador sin mayores modificaciones a lo largo de la década, mientras que en el caso de 
Colombia se puede observar un esfuerzo por incrementar las exportaciones de bienes manufacturados durante los primeros cuatro años de la década de los noventa; sin embargo, esta tendencia comienza a revertirse de manera sostenida en los años posteriores a la implantación de los programas de ajuste estructural.

Los anteriores resultados permiten establecer que la inversión extranjera directa está incidiendo de manera importante en la especialización productiva de los diferentes países y las formas particulares de inserción de las economías de éstos en la escena internacional. El masivo ingreso de nuevas inversiones para las actividades de manufactura en México se realiza con la perspectiva de crear plataformas de exportación para el mercado norteamericano. Mientras que, en los países restantes la inversión extranjera busca aprovechar, sobre todo, la generosa dotación de recursos naturales y energéticos de la región.

El señalamiento anterior sobre los efectos de la inversión extranjera en México, lleva a plantear la importancia que ha tenido la conformación de bloques regionales en el desarrollo de la actividad exportadora de los países de la región. Convendría, así, hacer algunas muy breves consideraciones con relación a la consolidación de los bloques regionales (TLCAN, MERCOSUR y Grupo Andino) y su influencia sobre el desempeño exportador de estos países.

En el caso de América Latina, el porcentaje de las exportaciones intrarregionales pasó de $12 \%$ en 1988 a $23 \%$ en el año de 1997, es decir, prácticamente se duplicó. En virtud de que las exportaciones totales casi se cuadruplicaron, se advierte que el valor de las exportaciones intrarregionales se incrementó más de siete veces.

La importancia de los bloques regionales se evidencia en el crecimiento del intercambio comercial entre los participantes de cada uno de ellos: Colombia y Venezuela se han convertido recíprocamente en importantes socios comerciales, al igual que Argentina y Brasil, mientras que México ya es el tercer socio comercial de Estados Unidos. Un buen porcentaje de estos intercambios bilaterales se basó en bienes manufacturados, lo cual permite inferir que con otras regiones se han acentuado las exportaciones de productos primarios.

En el caso de México, habría que hacer una consideración adicional: la importante contribución de la industria de la maquila al crecimiento del producto industrial y las exportaciones manufactureras. ${ }^{19}$ Algunos estudios revelan que un buen porcentaje del incremento de las exportaciones mexicanas de los últimos años ha corrido por cuenta de esta industria, en muchos casos cuestionada por la poca preocupación que muestra por los problemas ambientales y sociales.

19 De hecho, en el año 2000 la industria mexicana creció, impulsada por la maquila cuya producción aumentó un significativo 15\% (CEPAL, 2001). 


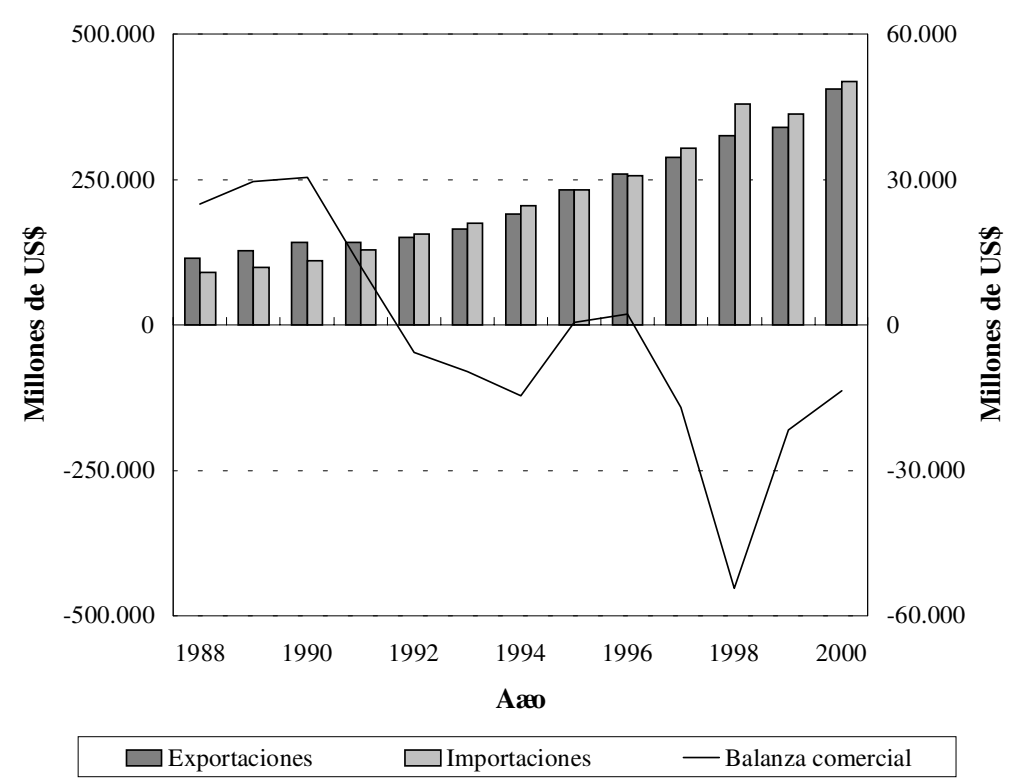

Gráfica 8. Balanza comercial de América Latina.

Fuente: CEPAL.

\section{El incremento del déficit comercial}

La apertura económica no sólo trajo un significativo incremento de las exportaciones sino también un aumento enorme de las importaciones. Éstas experimentaron un ritmo de incremento superior al de las exportaciones, lo cual generó un déficit comercial a lo largo de los últimos años, que se convirtió en uno de los problemas crónicos de las economías de la región durante los años noventa (véase Gráfica 8).

La apertura de los mercados latinoamericanos a principio de la década los noventa significó un incrementó del flujo de importaciones de productos manufacturados de proveedores tradicionales, como Estados Unidos, Japón y la Unión Europea. Por otra parte, permitió el ingreso de nuevos participantes en los mercados globales, especialmente del sudeste asiático, como Corea y China. ${ }^{20}$

Algunos elaboradores de política de la región estimaban que el déficit de la balanza comercial podría ser compensado por los ingresos de capital extranjero a través de la inversión extranjera directa y el capital financiero. Sin embargo, a pesar de los volúmenes crecientes de inversión extranjera directa, la volatilidad del capital financiero especulativo y la creciente transferencia de capital para cubrir el servicio de la deuda han incidido en un desempeño cada vez más negativo de la balanza de cuenta corriente (véase Gráfica 9), lo

20 Este factor ha tenido una implicación negativa adicional: la pérdida de puestos de trabajo con el consecuente descenso de la calidad de vida de una fracción importante de la población. Éste es un elemento que suele ser poco considerado a la hora de discutir el problema de la sustentabilidad. 


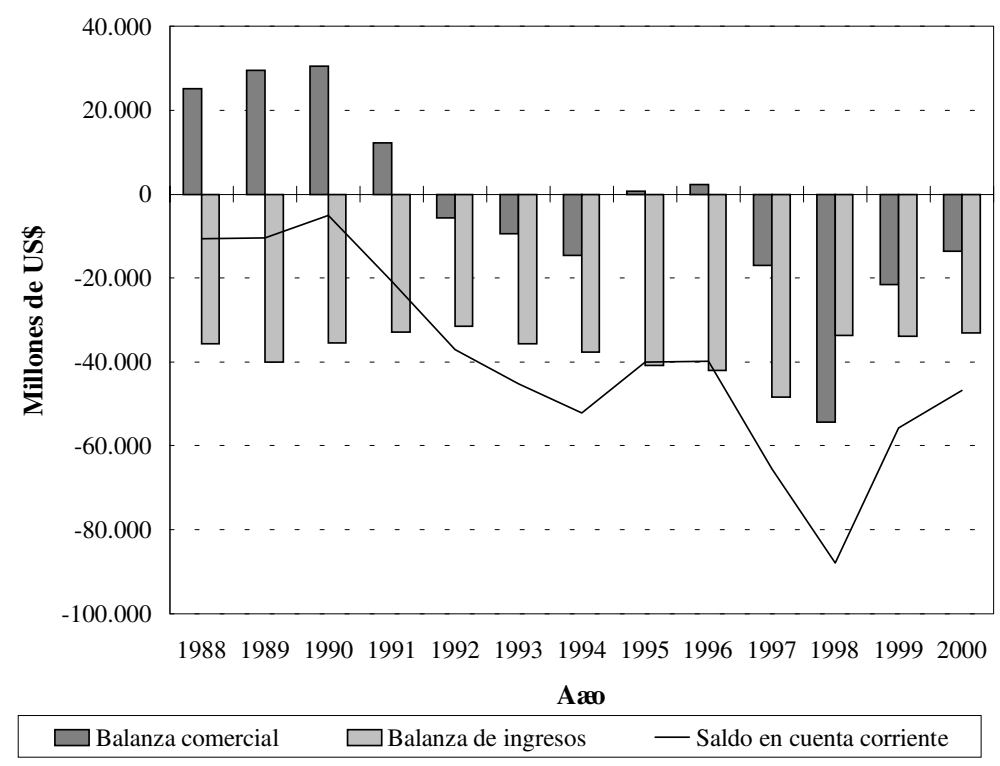

Gráfica 9. Balanza en cuenta corriente de América Latina.

Fuente: CEPAL.

que conforma una situación macroeconómica poco auspiciosa con relación a las posibilidades de avanzar hacia un modelo de desarrollo sustentable.

El desmedido incremento del saldo negativo en la cuenta corriente implicará mayores presiones sobre los sectores exportadores de los países de la región, en especial de los más competitivos, dentro de los cuales destacan, justamente, aquellos que se fundamentan en ventajas estáticas de carácter comparativo asociadas a la explotación de recursos naturales.

Por último, se analiza el problema que, probablemente, pueda comprometer con mayor seriedad las posibilidades de avanzar en la conformación de un modelo de desarrollo ambientalmente sustentable en la región: la deuda externa. Si bien el plan Brady, implantado a inicios de los años noventa, supuso una disminución de la carga de la deuda para Latinoamérica, durante la segunda parte de esa década se observó un extraordinario aumento del monto global de la misma (véase Tabla 2). Creció aceleradamente el ritmo de endeudamiento, bien a través de los préstamos de auxilio otorgados a Brasil, Argentina y México durante las sucesivas crisis (1995 y 1998 y 2002) o a través de programas de los organismos multilaterales y la banca privada a los diferentes países.

El progresivo incremento de la deuda externa determina que los países de la región se vean obligados a destinar crecientes montos de sus ingresos para poder cumplir los compromisos adquiridos con los organismos multilaterales y la banca internacional. El sostenido aumento de las exportaciones durante la década de los noventa — hay que recordar que casi se cuadruplicó- tenía que incidir en una mejora de la relación entre exportaciones y deuda (véase Gráfica 10). Sin embargo, eso no significa que se esté en vía de 
Tabla 2

Deuda externa de América Latina (millones de US\$)

\begin{tabular}{rrrrrrrr}
\hline Año & $\begin{array}{c}\text { América } \\
\text { Latina }\end{array}$ & Argentina & Brasil & Chile & Colombia & México & Venezuela \\
\hline 1988 & 413.446 & 58.473 & 113.469 & 18.960 & 17.960 & 100.900 & 31.586 \\
1989 & 417.936 & 63.314 & 115.096 & 17.520 & 17.604 & 95.100 & 31.566 \\
1990 & 439.775 & 60.973 & 123.439 & 18.576 & 17.848 & 101.900 & 36.615 \\
1991 & 465.722 & 61.334 & 123.811 & 17.319 & 17.335 & 117.552 & 36.000 \\
1992 & 484.194 & 62.766 & 135.949 & 18.964 & 17.277 & 117.534 & 38.447 \\
1993 & 528.030 & 72.209 & 145.726 & 19.665 & 18.908 & 131.717 & 40.836 \\
1994 & 564.821 & 85.656 & 148.295 & 21.768 & 21.855 & 142.199 & 40.981 \\
1995 & 617.947 & 98.547 & 159.256 & 21.736 & 24.928 & 169.699 & 37.519 \\
1996 & 638.878 & 109.756 & 179.935 & 22.979 & 29.513 & 163.499 & 34.120 \\
1997 & 664.150 & 125.091 & 199.998 & 26.701 & 32.036 & 149.028 & 31.330 \\
1998 & 744.905 & 141.943 & 241.644 & 31.691 & 33.895 & 160.258 & 30.250 \\
1999 & 759.328 & 145.955 & 241.468 & 34.167 & 33.626 & 166.381 & 32.596 \\
2000 & 737.700 & 147.667 & 236.151 & 36.837 & 33.264 & 148.780 & 31.545 \\
\hline
\end{tabular}

Fuente: CEPAL.

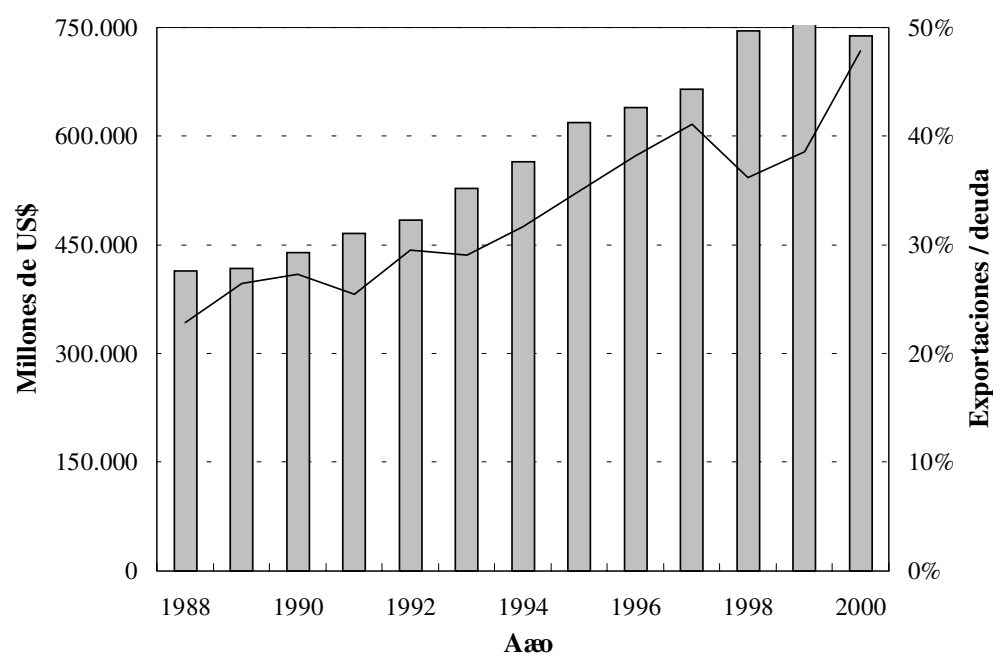

Gráfica 10. Fuente:

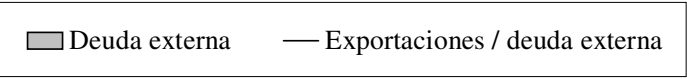

solucionar este grave problema. Un incremento tan significativo de los valores exportados y de la inversión extranjera directa permitiría esperar si no una disminución del monto global de la deuda, sí un aminoramiento en su ritmo de crecimiento. Pero, muy por el contrario, éste continúa incrementándose hoy hasta alcanzar niveles críticos.

Así, gran parte del esfuerzo exportador de la mayoría de los países de la región, basado significativamente en la explotación de recursos naturales, se destina a cumplir con los 
servicios de la deuda, con el agravante de que es prácticamente despreciable lo que se amortiza en capital. ${ }^{21}$

Este ritmo de transferencia de recursos desde la región hacia los países desarrollados plantea, además de un inobjetable cuestionamiento ético, serias dudas con relación a la racionalidad y viabilidad del modelo imperante, pues, ¿puede avanzarse en la conformación de un modelo de desarrollo sustentable de alcance global en medio de las desmesuradas asimetrías económicas imperantes?Y en términos más específicos de los postulados de la sustentabilidad, ¿hasta qué punto este modelo está siendo capaz de satisfacer las necesidades de la mayoría de los latinoamericanos de la actual generación? Y algo aun peor, ¿hasta qué punto está poniendo en peligro la capacidad y el derecho de las futuras generaciones de la región para satisfacer sus necesidades básicas?

\section{Conclusiones}

El desempeño económico y social de la mayoría de los países de la región durante la década de los noventa demuestra que si bien se avanzó en la corrección de algunas variables macroeconómicas fue poco lo que se logró en función de modificar una estructura productiva primaria exportadora, cuyos rasgos fundamentales evidencian el mantenimiento de un perfil muy poco sustentable. Este proceso ocurre en un contexto internacional caracterizado por una creciente complejidad de la actividad tecnoproductiva, ligada a la implantación y difusión del nuevo paradigma tecnoeconómico basado en la microelectrónica y caracterizado por un uso intensivo de la información.

La transición tecnoproductiva iniciada en la década de los setenta — desde un modelo basado en el uso intensivo de materias primas y energía a uno basado en el uso intensivo del conocimiento, en el que se observa un desacoplamiento progresivo entre el incremento del producto industrial y el consumo de recursos materiales y energéticos - lleva a pensar en la posibilidad de estar ante una transición que va más allá de un cambio de paradigma tecnoeconómico. Puede tratarse, incluso, de un cambio en la concepción de la naturaleza de los paradigmas; un proceso de evolución desde una perspectiva fundamentalmente tecnoeconómica a una perspectiva productivo-ambiental. Ésta se manifiesta con especial fuerza en los países desarrollados.

Un aspecto importante de este proceso de transformación es que la necesidad de mitigar y evitar el impacto de las actividades humanas sobre el ambiente y el imperativo de avanzar hacia un modelo de desarrollo sustentable están siendo fuertemente determinados

${ }^{21}$ Si bien no se dispone de datos precisos para los dos últimos años, puede señalarse que esta tendencia se ha agudizado alcanzando niveles críticos en la actualidad pues, sólo en el caso de Brasil, durante el año 2000 debió desembolsar más de 20 mil millones de dólares para cumplir con las obligaciones contempladas en el plan de ayuda del Fondo Monetario Internacional, acordado a inicios de 1999 y en los próximos años deberá destinar montos aun superiores para cumplir con el auxilio recientemente acordado. Mientras Argentina entró en default a comienzos de 2002, situación que amenaza con extenderse a otros países de la región. 
por elementos de carácter ético y político que en gran medida se contraponen a la perspectiva de liberalización económica propugnada por los diversos organismos multilaterales. En consecuencia, éstos elementos emergen como factores decisivos en la conformación y difusión del nuevo paradigma.

Las tentativas de modernización económica adelantada en América Latina durante la década de los noventa, alineadas dentro de la perspectiva de liberalización económica y concentradas en el ámbito macroeconómico, acentuaron la tendencia a basar el crecimiento económico en los sectores primarios de la economía. Esta situación se agravó en la última década por las condiciones desfavorables del mercado de las materias primas; además, no hubo mayor preocupación por las implicaciones ambientales de su explotación. Así, el perfil productivo conformado en la región, apunta hacia una inserción no sustentable de la economía regional.

Este proceso ha sido acompañado por el estancamiento de una serie de indicadores sociales y profundos desequilibrios en el sector externo de la economía. Los déficits en la balanza comercial y de pagos, y el acelerado incremento de los montos de la deuda externa, están comprometiendo los recursos económicos y materiales de la región, planteando grandes dudas acerca de las posibilidades de que la actual generación de latinoamericanos esté garantizando la capacidad de las futuras generaciones de satisfacer sus necesidades.

\section{Bibliografía}

Ávalos, I. "La industria venezolana: cinco años de ajuste sin política tecnológica”, Revista Espacios, vol. 14, núm. 2, 1993, pp. 19-32.

Baruk, J., "Innovativeness of Polish Enterprises in the Initial Period of System Transformation", Technovation, vol. 17, núm. 7, 1997.

Borregaard, N. y T. Bradley, "Impactos ambientales del comercio: análisis de tres sectores exportadores chilenos", Ambiente y Desarrollo, vol. 15, núm. 4, 1999.

Capra, F., La trama de la vida, Barcelona, Anagrama, 1998.

CCA, "El libre comercio y el medio ambiente: la imagen se aclara", Comisión para la Cooperación Ambiental de América del Norte, 2002.

CEPAL (varios años desde 1974 hasta 2001), Anuario estadístico de América Latina y el Caribe, Santiago de Chile, Comisión Económica para América Latina.
- Transformación productiva con equidad, Santiago de Chile, Comisión Económica para América Latina, 1990.

_- La inversión extranjera en América Latina y el Caribe, Informe 1997, Santiago de Chile, Comisión Económica para América Latina, 1998.

—_, La inversión extranjera en América Latina y el Caribe, Informe 1998, Santiago de Chile, Comisión Económica para América Latina, 1999.

— Estudio Económico de América Latina y el Caribe, Santiago de Chile, Comisión Económica para América Latina, 2001.

CYTED, Cien empresas innovadoras, Universidad de Valparaíso, Editorial Valparaíso, 1992.

Höhn, H., "Ética ambiental y política ambiental", en Thesing, J. y W. Hofmeister (editores), La protección del medio ambiente, conceptos y políticas, Buenos Aires, Konrad Adenauer-Stiftung, A.C., CIEDLA, 1997. 
Lacabana, M., "Impactos socioambientales de la nueva minería del oro en Venezuela", Cuadernos del CENDES, vol. 16, núm. 41, 1999, pp. 173-205.

Lacabana, M. y A. Mercado, "El futuro del trabajo. Reflexiones desde América Latina”, en S. Aranda (coordinador), Visiones del futuro. Economía, educación y trabajo, Caracas, CENDES-CDCH, Universidad Central de Venezuela, 1997.

Mercado, A., Desarrollo tecnológico en la industria de química fina de Brasil, Caracas, Fintec, 1995. , Aprendizaje tecnológico y desarrollo institucional: la experiencia de la industria química y petroquímica en Brasil y Venezuela, Caracas, tesis de doctorado, IVIC, 2000.

- y P. Testa, Tecnología y ambiente: el desafio competitivo de la industria química y petroquímica venezolana, Caracas, Fundación Polar-CENDES, 2001.

Messner, D., I. Dietrich, J. Friederi, R. Guttack, K. Kiehl y W. Klein, Hacia la competitividad industrial en Chile. El caso de la industria de la madera, Berlín, Instituto Alemán del Desarrollo, 1992.

Naim, M. (editor), Papers, Tigers \& Minotaurus. The Politics of Venezuela's Economic Reforms, Washington, Carnegie Endowment Book, 1993.

Peres, W., ¿Dónde estamos en política industrial?”, Revista de la CEPAL, núm. 51, Santiago de Chile, 1993.

Pérez, C., "Revoluciones tecnológicas y transformaciones socioinstitucionales", Caracas, CENDES, 1992.
"Revoluciones tecnológicas, cambios de paradigma y de marco socio-institucional", http://WWW.carlotaperez.org/articulos/ ficharevolucionestecnologicas.html, 1998.

Pirela, A. (editor), Cultura empresarial en Venezuela. La industria química y petroquímica, Caracas, Fundación Polar-CENDES, 1996.

Simonis, U., "La reorientación ecológica de la sociedad industrial", en Thesing, J. y W. Hofmeister (editores), La protección del medio ambiente, conceptos y políticas, Buenos Aires, Konrad Adenauer-Stiftung, A.C. CIEDLA, 1997.

Stiglitz, J., "Mi aprendizaje sobre la crisis económica mundial", Nueva Sociedad, junio-julio, Caracas, 2000.

-, El malestar de la globalización, Madrid, Santillana, 2002.

Suzigan, W. y A. Villela, Industrial Policy in Brazil, Instituto de Economía, Unicamp, Campinas, 1997.

World Commission on Environment and Development, Our common future, New York, Oxford University Press, 1987.

Tockman, J. "Impact of the Free Trade Area of the Americas on Forests. A forest-specific analysis of the draft text of the FTAA", http://WwW. tradeandforests.org/documents/2001/ ftaa_forests.pdf), 2001. 